\section{GÊNERO NOS CURSOS DE ENGENHARIA DE UMA UNIVERSIDADE TECNOLÓGICA BRASILEIRA}

\author{
Marilia Gomes de Carvalho \\ y Josimeire de Lima Sobreira \\ Universidade Tecnológica Federal do Paraná-UTFPR
}

\section{GÉNERO EN LOS CURSOS DE INGENIERÍA DE UNA UNIVERSIDAD TECNOLÓGICA BRASILEÑA}

RESUMEN: La investigación en una Universidad Tecnológica de Brasil entre estudiantes de los cursos de ingeniería ha mostrado que las mujeres no ocupan más que 12\% (en general) de las plazas de la Institución. El curso con más estudiantes es el de Ingeniería Civil, mientras el curso con el más pequeño número de mujeres es el de Mecánica. La metodología de la investigación ha sido cualitativa. Las entrevistas con chicas-chicos de los cursos investigados revelaron que hay discriminación entre los estudiantes que no consideran a sus compañeras de curso competentes para los estudios de ciencias exactas. Para que sean respetadas ellas tienen que estudiar mucho más que ellos, pero, aunque logren muy buenas evaluaciones, reconocen que en el mercado laboral tendrán menos oportunidades de trabajo que sus colegas. Entretanto, los cambios de género entre los y las estudiantes evidencian que las mujeres están conquistando espacios importantes.

PALABRAS CLAVE: Género, ingeniería, estudiantes.
RESUMO: A pesquisa em uma Universidade Tecnológica brasileira entre estudantes de cursos de Engenharia mostrou que as mulheres não ocupam mais que $12 \%$ (em geral) das vagas existentes na Instiutição. 0 curso mais procurado pelas estudantes é o de Engenharia Civil. Por outro lado, o curso que apresenta o menor número de mulheres é o de Engenharia Mecânica. A metodologia da pesquisa foi qualitativa. As entrevistas com moças e rapazes dos cursos investigados revelaram que existe discriminação enre os estudantes que não consideram suas colegas de Curso competentes para estudarem as Ciências Exatas. Para que sejam respeitadas elas têm que estudar muito mais do que eles, porém, mesmo quando conseguem boas notas, reconhecem que terão menores oportunidades no mercado de trabalho que os seus colegas. Entretanto, mudanças de gênero entre os e as estudantes evidenciam que as mulheres estão conquistando espaços importantes.

PALAVRAS-CHAVE: Gênero, Engenharia, estudantes.

\title{
GENDER IN ENGINEERING STUDIES AT A BRAZILIAN TECHNICAL UNIVERSITY
}

\begin{abstract}
The research on a Technological University of Brazil, among students in Engineering, revealed that women occupy no more than $12 \%$ (in general) of the places at the Institution. The university study that the girls most prefer is the Engineering of Buildings and the other one, where there are the least number of women, is Mechanics Engineering. The qualitative research with the students, made by interviews, showed that there is a gender discrimination among them. The boys do not consider their schoolmates competents for the exact sciences. The girls have to do a greater effort than the boys to success and to be respected by them. But even so they recognize that will not have the same opportunities of work that the men will. However, gender changes among the students are evidences that women have reached important places at the technological field.
\end{abstract}

KEY WORDS: Gender, engineering, students. 


\section{INTRODUÇÃO}

Este artigo trata dos resultados de uma pesquisa realizada na Universidade Tecnológica Federal do Paraná - Campus de Curitiba, entre os (e as) estudantes de quatro cursos de engenharia, a saber: Industrial Mecânica, Electrônica, Electro Técnica e Produção Civil. Os objetivos desta investigação foram: 1. conhecer como estão representadas as relações de gênero entre as moças e rapazes nos cursos da área tecnológica e 2. conhecer as expectativas profissionais dos (e das) estudantes'.

Adotou-se a metodologia qualitativa, utilizando-se as técnicas de entrevista aberta com as (e os) estudantes e a observação direta no ambiente universitário. Foram entrevistados 11 moças e 9 rapazes, completando um total de 20 estudantes entrevistadas/os. Cada entrevista teve a duração de aproximadamente uma hora a uma hora e meia e tratava de temas relacionados com os objetivos da investigação.

A escolha das técnicas qualitativas se justifica tendo em vista o objetivo da pesquisa, ou seja, a busca das percepções e das representações dos (e das) estudantes. 0 método quantitativo não permite chegar ao nivel de subjetividade que a pesquisa propunha, portanto as entrevista e a observação realizada no campo de pesquisa ajudaram a aprofundar os resultados. Os dados quantitativos foram também utilizados para mostrar numericamente a situação de desigualdade de gênero que existe nos cursos de tecnologia.

0 artigo está estruturado da seguinte maneira: primeiramente trata-se da situação numérica das mulheres nos cursos de engenharia e no mercado de trabalho, com uma breve descrição da Instituição investigada. Em seguida apresenta-se os resultados da pesquisa qualitativa, discutindo-os em termos das relações de gênero.

\section{MULHERES E HOMENS NAS ENGENHARIAS: UNA ABORDAGEM QUANTITATIVA}

Muitas pesquisas já foram realizadas no Brasil para mostrar a desigualdade de gênero que existe nas engenharias². Em todas elas há dados quantitativos que o compravan. Outros estudos sobre gênero, ciência e tecnologia na Amécica Latina também chegam aos mesmos resultados ${ }^{3}$. Portanto não há dúvidas que este é um fenômeno conhecido pelos pesquisadores que se dedicam aos estudos de gênero.

Esta desigualdade existe porque ciência e tecnologia, ainda hoje, são consideradas universos masculinos, aonde a presença feminina permaneceu invisivel, mesmo quando as mulheres produzem ciência e se utilizam de tecnologias. 0 universo da ciência da tecnologia foram construídos através de características masculinas, razão pela qual, para que as mulheres possam participar deles, necessitam "falar" a linguagem dos homens. A socialização das meninas não as prepara para trabalharem com equipamentos técnicos da mesma maneira que prepara os meninos. As atividades da infância são separadas em experiências que incentivam os meninos para a objetividade, enquanto as experiências das meninas as incentivam a desenvolver características mais subjetivas. Essa dualidade é construída por toda a vida de homens e mulheres de maneira tal que quando chegam na idade de escolher uma profissão, fazem-no também dicotomicamente, de acordo com as expectativas sociais ${ }^{4}$.

Os dados apresentados a seguir falam por si. As profissões e as diferentes áreas da ciência estão divididas em "masculinas e femininas", de acordo com o número mais significativo de homens e mulheres em cada uma delas. Na Tabela I pode-se observar que as áreas "femininas", ou seja, as que possuem o maior número de mulheres são educação, serviços, saúde e bem estar social (atividades do

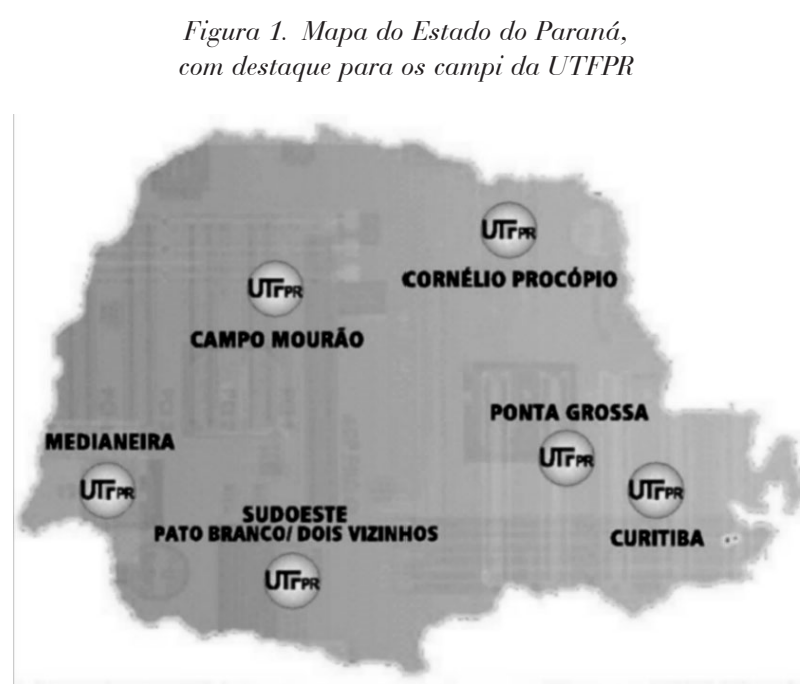

Fuente: Revista da transição do CEFET-PR em Universidade. Edição Especial, Outubro de 2005. 

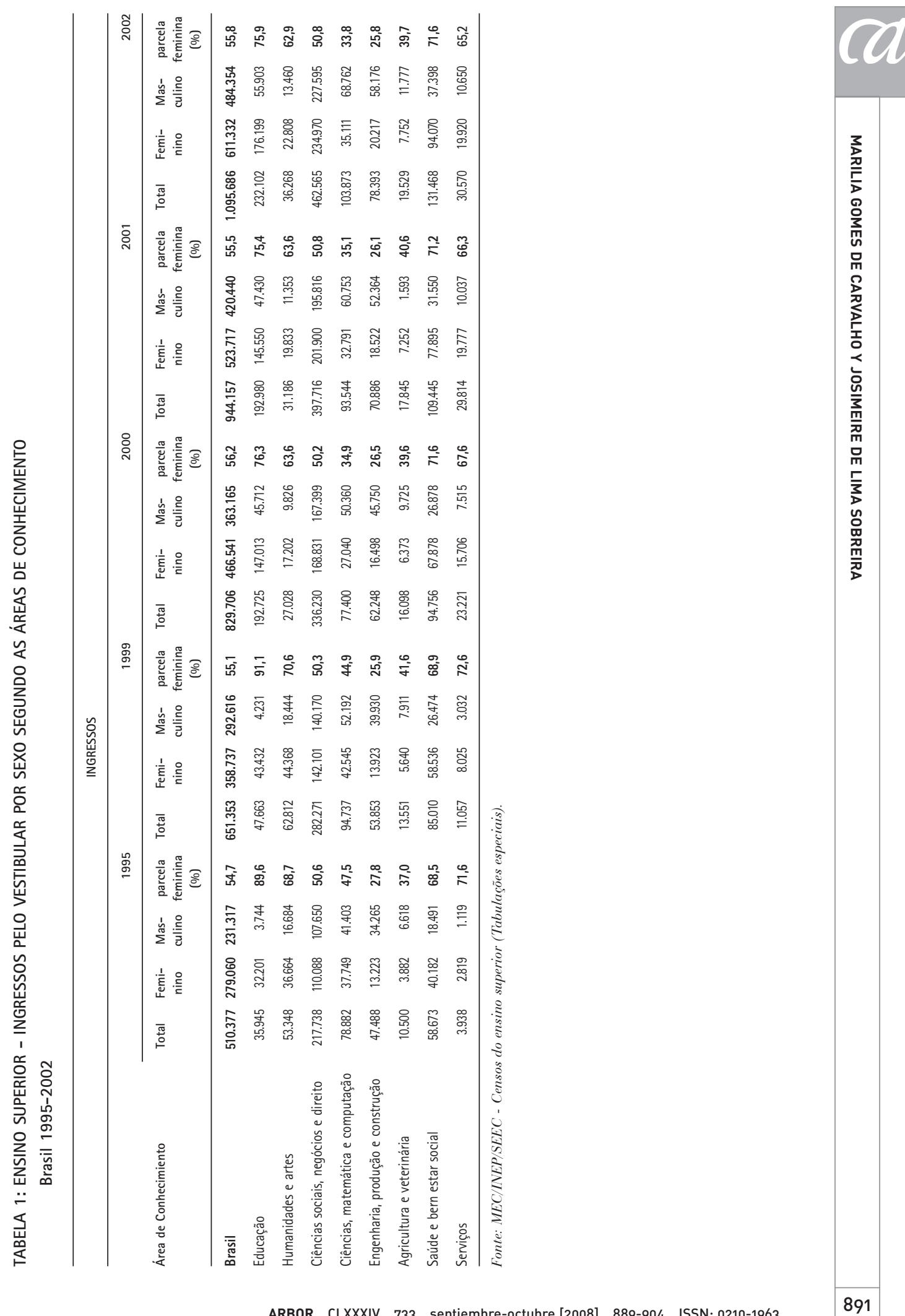
"cuidado"), humanidades e arte (atividades subjetivas). As áreas das ciências exatas, como matemática, computação, engenharias, agricultura e veterinária (atividades técnicas e objetivas) possuem maior número de homens e são consideradas masculinas.

Pode-se dizer também que estes números pouco se alteraram nos sete anos analisados, apesar do movimento das mulheres para uma participação mais efetiva nas ciências exatas e tecnológicas. Por outro lado, pode-se observar que a porcentagem total da parcela feminina no ensino superior é um pouco maior do que a dos homens, o que significa que as mulheres estão estudando mais.

Vamos mostrar a seguir os dados quantitativos sobre as matrículas dos estudantes da Universidade Tecnológica Federal do Paraná - Campus de Curitiba, no Brasil, em seus diferentes cursos de engenharia. No entanto julga-se importante apresentar antes uma breve descrição desta Universidade.

A UTFPR ${ }^{5}$ possui uma tradição de mais de 90 anos, é considerada centro de referência do ensino tecnológico do Sul do País, e tem por objetivo "educar com padrão de excelência", evoluindo permanentemente e adaptandose às mudanças, às exigências e aos constantes avanços tecnológicos.

A história da UTFPR teve início em 1910, quando foi implantada a Escola de Aprendizes Artífices do Paraná. Inicialmente era uma instituição destinada às camadas pobres da população e aos menores marginalizados, predominantemente meninos. Desde sua criação, percebe-se que a escola teve a intenção de atender ao público masculino, especificamente aos menores transgressores (e não às menores), que "alteravam a paz" das ruas da capital paranaense.

Em 1937, a escola passou a oferecer o ensino fundamental em consonância com a realidade da época, sendo então denominada Liceu Industrial de Curitiba. Em 1959, com a reforma do ensino industrial, a legislação unificou o ensino técnico no Brasil que até então era dividido em ramos diferentes. A Escola ganhou autonomia, bem como nova alteração no nome: passou a chamar-se Escola Técnica Federal do Paraná e a ser considerada como unidade escolar padrão no Estado 6 .
Até 1978, a instituição caracterizava-se pela formação de técnicos (nivel médio). Neste ano a antiga Escola Técnica transforma-se no Centro Federal de Educação Tecnológica do Paraná (CEFET-PR), ao introduzir os primeiros cursos de engenharia industrial, sendo, inicialmente, engenharia elétrica (com ênfase em eletro técnica), engenharia industrial mecânica e engenharia de produção civil.

No ano de 2005, o então CEFET-PR passa por uma nova transformação federal, tornando-se a primeira Universidade Tecnológica do País, a UTFPR, tendo sido instalada em Curitiba e em todos os 5 campi do interior do Estado ${ }^{7}$.

A UTFPR ${ }^{8}$ tem como foco principal a graduação, a pósgraduação e a extensão. Oferece 41 cursos superiores de Tecnologia, de Engenharia e de Ciências, além de cursos de pós-graduação lato-sensu e stricto sensu (mestrados e doutorados). Oferta também os seguintes níveis de ensino: Ensino Médio e Técnico Integrado, de acordo com as exigências do mercado de trabalho.

O Campus Curitiba da UTFPR é o mais tradicional de todos e tem uma estrutura conservadora. Pode-se dizer que ele possui uma visão androcêntrica do mundo, uma vez que o ensino técnico e profissionalizante se preocupou em atender mais a comunidade masculina. Por estar inserida dentro de uma sociedade machista, também absorveu este modelo que foi, ao longo do tempo, tornando-se cada vez mais forte, enraizado e cristalizado.

Dentro deste contexto, observou-se que todos os cursos de engenharia analisados neste trabalho apresentam um reduzido número de mulheres, cerca de $10 \%$ do total de estudantes matriculados. É possível observar este fato na tabela 2 a seguir.

Esta tabela 2 confirma que permanece majoritária a presença de homens nos cursos de engenharia e fica evidente que houve um crescimento lento e progressivo no ingresso de moças nos cursos de engenharia da UTFPR na década de 90.

$\mathrm{Na}$ engenharia eletrônica, observa-se uma pequena variação no número de alunas matriculadas ao longo da década analisada. No ano de 1991, matricularam-se 08 moças, assim como em 2000. 0 ano de menor ingresso feminino foi 1992, com apenas 04 matriculadas, e o de maior número de matriculadas foi 1994, com 10 alunas. Em engenharia 
TABELA 2: DISTRIBUIÇÃO POR GÊNERO, DO CORPO DISCENTE DOS CURSOS DE ENGENHARIA DA UTFPR, CAMPUS CURITIBA, $1991-2000$

\begin{tabular}{|c|c|c|c|c|c|c|c|}
\hline \multirow[b]{2}{*}{ Ano } & \multirow[b]{2}{*}{ Gênero } & \multicolumn{4}{|c|}{ CURSO } & \multirow[b]{2}{*}{ Total } & \multirow[b]{2}{*}{$\%$} \\
\hline & & $\begin{array}{c}\text { Eng. } \\
\text { Eletrônica }\end{array}$ & $\begin{array}{l}\text { Eng. } \\
\text { Eletrotécnica }\end{array}$ & $\begin{array}{l}\text { Eng. } \\
\text { Civil }\end{array}$ & $\begin{array}{l}\text { Eng. } \\
\text { Mecânica** }\end{array}$ & & \\
\hline \multirow[t]{2}{*}{1991} & $M$ & 72 & 74 & 34 & 0 & 180 & $90 \%$ \\
\hline & $\mathrm{F}$ & 8 & 6 & 6 & 0 & 20 & $10 \%$ \\
\hline \multirow[t]{2}{*}{1992} & $M$ & 76 & 73 & 25 & 78 & 252 & $90 \%$ \\
\hline & $\mathrm{F}$ & 4 & 7 & 15 & 2 & 28 & $10 \%$ \\
\hline \multirow[t]{2}{*}{1993} & $M$ & 74 & 75 & 25 & 78 & 252 & $90 \%$ \\
\hline & $\mathrm{F}$ & 6 & 5 & 15 & 2 & 28 & $10 \%$ \\
\hline \multirow[t]{2}{*}{1994} & $M$ & 70 & 73 & 28 & 75 & 246 & $87,9 \%$ \\
\hline & $\mathrm{F}$ & 10 & 7 & 12 & 5 & 34 & $12,1 \%$ \\
\hline \multirow[t]{2}{*}{$1995^{*}$} & $M$ & 0 & 0 & 0 & 0 & 0 & - \\
\hline & $\mathrm{F}$ & 0 & 0 & 0 & 0 & 0 & - \\
\hline \multirow[t]{2}{*}{1996} & $M$ & 74 & 67 & 27 & 73 & 241 & $86,1 \%$ \\
\hline & $\mathrm{F}$ & 6 & 13 & 13 & 7 & 39 & $13,9 \%$ \\
\hline \multirow[t]{2}{*}{1997} & $M$ & 71 & 68 & 27 & 72 & 238 & $85 \%$ \\
\hline & $\mathrm{F}$ & 9 & 12 & 13 & 8 & 42 & $15 \%$ \\
\hline \multirow[t]{2}{*}{1998} & $M$ & 72 & 72 & 50 & 74 & 268 & $83,8 \%$ \\
\hline & $\mathrm{F}$ & 8 & 8 & 30 & 6 & 52 & $16,3 \%$ \\
\hline \multirow[t]{2}{*}{1999} & $M$ & 75 & 70 & 50 & 69 & 264 & $82,5 \%$ \\
\hline & $F$ & 5 & 10 & 30 & 11 & 56 & $17,5 \%$ \\
\hline \multirow[t]{2}{*}{2000} & $\mathrm{M}$ & 72 & 76 & 53 & 72 & 273 & $85,3 \%$ \\
\hline & $\mathrm{F}$ & 8 & 4 & 27 & 8 & 47 & $14,7 \%$ \\
\hline
\end{tabular}

Fonte: Comissão de vestibulares, CEFET-PR, unidade Curitiba-20049.

eletro técnica, percebe-se maior oscilação de matrículas femininas. Os anos de maior ingresso feminino foram 1996 e 1997, respectivamente, com 13 e 12 matriculadas, contudo, 0 ano 2000 marca uma forte retração, com apenas 04 moças matriculadas.

0 curso de engenharia civil inicia a década de 90 com apenas 06 matriculadas, ou $15 \%$ do universo de alunos matriculados e 0 ano 2000 registra 27 matrículas femininas e 53 masculinas, o que significa que cerca de $30 \%$ das vagas foram preenchidas por moças. Vale ressaltar que o curso de engenharia civil foi reestruturado em 1998, passando a ofertar 80 vagas e não mais 40 como era anteriormente. Foi o curso que mais sofreu um aumento da participação feminina na década de 90 .

0 curso de engenharia mecânica também apresentou um significativo aumento, passando de nenhuma matrícula feminina em 1991, para 08 em 2000, o que representa atualmente $10 \%$ das matrículas neste curso, isto é, das 80 vagas ofertadas, 08 foram preenchidas por moças. As pessoas em geral (e a própria Instituição) continuam considerando-o um curso mais indicado para atender ao público masculino. 
Observando a tabela, verificar-se-á que houve um aumento geral no número de moças que ingressaram na UTFPR na década passada, mas dificilmente ultrapassando os $20 \%$ dos/as alunos/as matriculados/as. Este fato é explicado por Saraiva $(2003$, p. 5) que declara que "desde cedo as mulheres são ensinadas de que são pouco dotadas para o raciocínio abstrato, para o trato com o mundo da produção, para a liderança e para tomadas de decisões, portanto optar por um curso de engenharia significa aceitar o desafio de ultrapassar as limitações femininas".

Um outro campo que permite analisar a situação de desigualdade de gênero nas engenharias é o mercado de trabalho. A participação das mulheres esteve, ao longo de toda a década de 90 , em torno de $10 \%$, o que comprova ser ainda um espaço masculino (Lombardi, 2004).

As mudanças econômicas que marcaram a década de 90, como a abertura de mercado e a implantação do Plano Real, contribuíram para que o mercado de trabalho no setor das engenharias fosse atingido negativamente, isto é, ocorreu uma redução dos postos de trabalho, o que afetou, sobretudo, a mulher engenheira (Lombardi, 2004).

Em 1990, dos 172.788 postos de trabalho, 25.237 vagas eram ocupadas por mulheres engenheiras, uma década mais tarde, ou seja, em 2000, esse número foi reduzido para 17.366. Houve, portanto, uma redução em torno de $30 \%$ de vagas. Estes números revelam o fato de que foram as engenheiras quem mais perderam com o crescente desemprego nesta área no Brasil, nesta década. Por outro lado, os engenheiros, no mesmo período, tiveram uma redução em torno de $25 \%$. Este dado mostra que, mesmo tendo um nível de instrução equivalente ao dos homens, as mulheres continuam sendo discriminadas no mercado de trabalho. Lombardi (2005) acrescenta ainda um dado mais recente, em 2002, das 139.287 vagas existentes para os/as profissionais da engenharia, 119.396 foram preenchidas por engenheiros, e apenas 19.891 foram preenchidos por engenheiras. Este dado é bastante revelador, uma vez que mostra uma área ainda refratária à mulher.

Um outro dado relevante é que, à medida que ocorre a dispensa de funcionários, mais funções assumem aqueles e aquelas que permaneceram no emprego, fato este, aliás, comum aos nossos dias, isto é, as empresas demitem, e aqueles que ficam são obrigados a assumir as funções daqueles que não estão mais presentes no ambiente corporativo (Lombardi, 2004). Portanto, o/a profissional da engenharia atual deve ter um perfil multifuncional, pois suas atribuições vão além do estrito conhecimento técnico.

Gráfico 1. Evolução do emprego para engenheiros, segundo o sexo, no Brasil-1990-2000

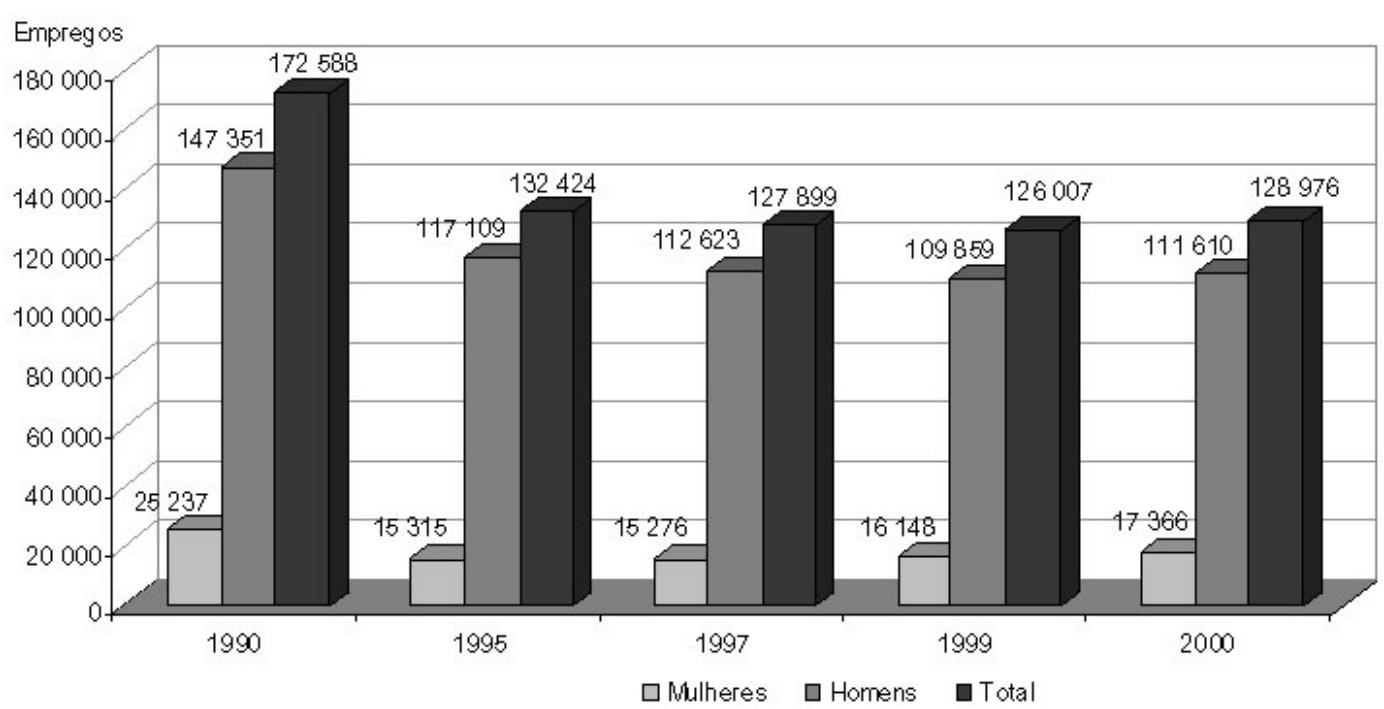

Fuente: RAIS 2000. Brasilia: Ministério do Trabalho e Emprego. 
TABELA 3: PARCELA FEMININA NOS EMPREGOS PARA ENGENHEIROS, SEGUNDO A ESPECIALIDADE, NO BRASIL - 1990-2000 (\%)

\begin{tabular}{|c|c|c|c|c|c|}
\hline ESPECIALIDADES & 1990 & 1995 & 1997 & 1999 & 2000 \\
\hline 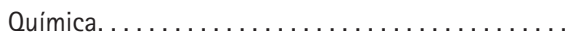 & 20,7 & 20,5 & 22,3 & 23,9 & 25,1 \\
\hline Organização e métodos. . & $(1) \ldots$ & 26,3 & 24,1 & 24,2 & 24,3 \\
\hline Civil.................... & 13,7 & 14,0 & 14,7 & 15,5 & 15,8 \\
\hline Outras $\ldots \ldots \ldots \ldots \ldots \ldots \ldots \ldots \ldots \ldots \ldots$ & 12,3 & 11,7 & 12,2 & 13,5 & 14,5 \\
\hline Produção. . . . . . . . . . & 8,8 & 7,8 & 8,7 & 10,3 & 10,5 \\
\hline Minas e geologia...$\ldots \ldots \ldots \ldots \ldots \ldots \ldots$ & 14,0 & 10,1 & 10,0 & 9,6 & 10,5 \\
\hline Eletricidade e eletrônica.... & 6,7 & 7,2 & 7,8 & 8,2 & 9,2 \\
\hline 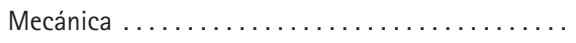 & 4,3 & 3,8 & 4,0 & 4,4 & 4,9 \\
\hline Metalurgia $\ldots \ldots \ldots \ldots \ldots \ldots \ldots \ldots \ldots$ & 1,6 & 3,8 & 5,6 & 5,1 & 4,6 \\
\hline Total ..... & 14,6 & 11,6 & 11,9 & 12,8 & 13,5 \\
\hline
\end{tabular}

Fonte: RAIS 2000. Brasilia: Ministério do Trabalho e Emprego.

No entanto, ainda que essas mulheres estejam ocupando novos e promissores espaços de trabalho, nos quais sua inserção tem características bastante semelhantes às dos homens, elas permanecem submetidas a uma desigualdade de gênero presente em todos os escalões do mercado de trabalho, ou seja, ganham menos do que seus colegas de profissão.

É importante ressaltar que, das atividades de engenharia, depois da Engenharia Química, a Engenharia Civil é a que mais absorve mulheres no mercado de trabalho, sendo o ramo da engenharia que apresenta mais engenheiras em atividade, apesar do preconceito, frente àquela engenheira que realiza funções em obras.

Pode-se verificar na tabela a seguir que a Engenharia Elétrica (Eletrônica e Eletro técnica) é uma das especialidades que mais tem tido aumento no número de alunas e de profissionais femininas no mercado de trabalho. 0 mesmo não acontece com a Engenharia Mecânica, que ainda permanece um reduto de homens.

De acordo com Lombardi, "a criação de novas especialidades no ensino de engenharia (...) incidiu especialmente sobre as opções femininas que, até meados dos anos 90, encontravam-se mais concentradas nas engenharias civil e química" $(2005,88)$. Este fato revela a existência da segregação feminina, tanto na escola quanto fora dela. Sobre as novas especialidades, a tabela 3 é reveladora, uma vez que ela aponta para a presença de várias ramificações dentro das engenharias, e conseqüentemente, crescente presença feminina nestas áreas.

Observa-se, contudo que, apesar dos novos ramos, as mulheres continuaram concentradas nas engenharias química e civil, além da organização e métodos. Vale ressaltar que os ramos que são tradicionais guetos masculinos, como as engenharias mecânica e metalúrgica, permaneceram com uma reduzida, mas crescente, participação feminina.

Vejamos a tabela 4.

Estes dados revelam a segregação existente no campo das engenharias. Os setores que mais absorveram engenheiras em 2000 foram a administração pública, a defesa e a seguridade social, o setor de saúde e serviços sociais e o setor de serviços coletivos. As engenheiras inserem-se mais facilmente nestas áreas, porque são espaços, cuja mão-deobra é tradicionalmente feminina, e, portanto, lugar onde elas estão presentes há mais tempo (Lombardi, 2005). Por outro lado, os homens permanecem majoritariamente no setor industrial.

Portanto os dados quantitativos mostram que, tanto no mercado de trabalho quanto no ensino tecnológico de nível 
TABELA 4: EMPREGOS PARA ENGENHEIROS, SEGUNDO O SETOR DE ATIVIDADES E O SEXO, NO BRASIL - 2000 (\%)

\begin{tabular}{|c|c|c|c|c|}
\hline Setores de atividades & Homens & Mulheres & Total & Parcela feminina (1) \\
\hline Indústria de transformação $\ldots \ldots \ldots \ldots \ldots \ldots \ldots$ & 26,8 & 17,1 & 25,5 & 9,0 \\
\hline \multicolumn{5}{|l|}{ Atividades imobiliárias, administração de aluguéis, consul- } \\
\hline toria e serviços prestados à empresas. ................. & 16,2 & 18,8 & 16,6 & 15,3 \\
\hline Construção civil $\ldots \ldots \ldots \ldots \ldots \ldots \ldots \ldots \ldots \ldots \ldots \ldots \ldots \ldots \ldots \ldots \ldots \ldots \ldots \ldots \ldots$ & 14,6 & 13,2 & 14,4 & 12,4 \\
\hline Administraçao pública, defesa e seguridade social ....... & 12,3 & 25,8 & 14,1 & 24,7 \\
\hline Transportes, amazenagem e comunicações .......... & 8,4 & 7,1 & 8,2 & 11,6 \\
\hline Produção e distribuição de água, gás, energia........... & 7,9 & 5,6 & 7,6 & 9,9 \\
\hline Comércio atacadista e varejista................ &, 3 & 3,3 & 4,2 & 10,5 \\
\hline Agricultura, pecuária, extração florestal e pesca......... & 3,2 & 2,6 & 3,1 & 11,5 \\
\hline \multicolumn{5}{|l|}{ Outros (serviços coletivos, sociais, pessoais, instituições } \\
\hline internacionais, etc.) $\ldots \ldots \ldots \ldots \ldots \ldots \ldots \ldots \ldots \ldots$ & 1,9 & 0,1 & 2,0 & 18,5 \\
\hline Indústrias de extração mineral. . . . . . . . . . . . . . . . . . & 1,6 & 0,6 & 1,5 & 5,8 \\
\hline Intermediação financeira (bancos, seguros, etc.) ........ & 1,3 & 1,0 & 0,9 & 14,7 \\
\hline 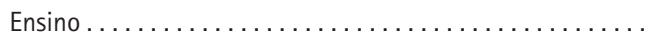 & 0,9 & 1,0 & 0,9 & 14,7 \\
\hline Saúde e serviços sociais ........ & 0,4 & 0,8 & 0,5 & 22,5 \\
\hline Alimentação e hospedagem . . . . . . . . . . . . . . . . . & 0,1 & 0,1 & 0,1 & 15,3 \\
\hline Total $\ldots \ldots \ldots \ldots \ldots \ldots \ldots \ldots \ldots \ldots \ldots \ldots \ldots \ldots \ldots \ldots \ldots$ & 100,0 & 100,0 & 100,0 & 13,5 \\
\hline
\end{tabular}

Fonte: RAIS 2000. Brasília: Ministério do Trabalho e Emprego.

(1) Percentural dos empregos feminios sobre o total dos empregos de cada setor.

superior, há uma tendência para a reprodução das representações sociais tradicionais, ou seja, as áreas das engenharias ainda são majoritariamente masculinas $\mathrm{e}$, dentro delas, as que mais absorvem as mulheres são justamente aquelas associadas aos padrões de gênero socialmente construídos.

\section{Resultados da PESQUiSA QuALITATIVA}

Os métodos qualitativos de pesquisa permitiram aprofundar situações e encontrar explicações de cunho subjetivo que ajudam a compreender como as desigualdades de gênero que estão evidenciadas nos dados quantitativos apresentados anteriormente foram construídos e vêm sendo reproduzidos nos casos específicos analisados. As entrevistas realizadas com os (e as) estudantes revelaram como eles (e elas) percebem as relações de gênero nos cursos de engenharia, asim como suas expectativas professionais.

0 reduzido número de mulheres nos cursos de engenharia da Instituição investigada encontra uma explicação para as pessoas em geral que interpretam as ciências exatas como áreas do conhecimento mais difíceis (hard), enquanto que as ciências da vida, as humanidades $e$ as ciências sociais, são mais fáceis (soft) (Schienbinger, 2001). Este exemplo demonstra uma visão sexista do conhecimento, através da qual o homem, por ser considerado mais "racional", teria mais facilidade para as ciências exatas, enquanto a mulher, que é sempre vista como um ser emotivo, estaria mais inclinada para as áreas das humanidades e do cuidado. 
Ainda hoje, quando uma mulher opta por cursar engenharia, ela sofre pressão da sociedade, fato este percebido, pelas falas de algumas das entrevistadas:

"minha mãe não gostou muito não da minha escolha, ela acha que não é área para mulher. Minha mãe queria que eu fizesse Direito." (Entrevistada U).

"a mulher não é muito incentivada para a área de exatas (...) Acho que ainda acontece de muita gente achar que a mulher não tem capacidade para engenharia". (Entrevistada S).

Tanto os rapazes quanto as moças alegaram que o motivo para cursar engenharia, está no fato de gostarem de matemática e cálculo, isto é, da área de ciências exatas.

"Eu resolvi fazer Civil porque eu sempre gostei de fazer cálculo. Desde pequena eu fiz Kumon". (Entrevistada C).

"eu já gostava de matemática, dai pensei em fazer alguma coisa nessa área" (Entrevistado D).

Percebe-se também em alguns depoimentos, a influência familiar e dos professores nas decisões:

"... vim fazer engenharia porque meus primos estudam aqui e amam o curso, daí eles me convenceram". (Entrevistada A). "toda minha familia trabalha com engenharia e tecnologia, além disso, sempre tive facilidade com números". (Entrevistado J).

"aqui (na UTFPR) tive bons professores, que me ajudaram a descobrir a engenharia". (Entrevistado 0).

Outros vêem a engenharia como uma carreira que dá status e dinheiro.

"... no começo estava na dúvida entre engenharia e matemática, mas aí vi que matemática não dá dinheiro e desisti da idéia". (Entrevistado E).

"o leque que se abre, você consegue emprego em qualquer lugar, em escola, em empresa, em loja, como administrador, ..." (Entrevistada G).

"é um curso que abre mais oportunidades". (Entrevistado N).

Observa-se que há uma preocupação entre os/as entrevistados/as quanto à remuneração, predominando uma visão de que o curso de engenharia vai fornecer uma carreira sólida e bem remunerada.
Todos/as possuem uma visão idealizada da engenharia, acreditando que as condições do mercado de trabalho são mais favoráveis para quem escolhe esta profissão. Por outro lado, os cursos das áreas de humanidades, são marcados por menor prestígio e conseqüente remuneração mais baixa.

Vale ressaltar que todos/as discentes vêem as moças como mais dedicadas, elas se esforçam mais do que os rapazes, além disso, têm que estar provando todo o tempo que são tão "boas e competentes quanto os rapazes".

Mas, apesar de as mulheres ingressarem nos cursos de engenharia (o que poderia significar que estão rompendo com os padrões tradicionais de gênero) elas continuam reproduzindo os papéis socialmente construídos, isto é, elas mesmas afirmam que por serem mais cuidadosas, atenciosas, terão mais chances do que os homens em algumas tarefas.

"... para mim, a mulher tem hoje algumas vantagens sobre os homens, por exemplo: ela é mais cuidadosa, atenciosa e detalhista, e isso é bom para as engenheiras". (Entrevistada S). "a mulher é mais organizada e atenciosa, o que contribui para desempenhar melhor sua função no trabalho". (Entrevistado Q).

Vários entrevistados relataram que um empecilho para a mulher engenheira está na falta da força física, fato curioso, uma vez que os discentes se esquecem de que o uso da tecnologia dispensa, em muitos casos, esta característica.

"os homens não podem mais duvidar da capacidade intelectual das mulheres, talvez da capacidade física (de realizar um trabalho braçal, por exemplo, descascar um fio)". (Entrevistada P).

"talvez o menino tenha mais facilidade de arrumar um estágio e/ou emprego, por causa de sua força física (para apartar briga, carregar peso), mas não por saber mais do que as meninas" (Entrevistada C).

Estas declarações apresentam um dado relevante, uma vez que consideram a mulher incapaz de fazer qualquer tipo de esforço físico (como descascar um fio), ao contrário do homem que, segundo essa visão binária, é forte e suficientemente capaz de realizar tarefas "pesadas". Pode-se dizer que a imagem do homem está arraigada no imaginário 
coletivo que considera a força física uma capacidade masculina e imprescindivel para a realização de determinadas atividades, mesmo quando o uso cada vez mais intenso da tecnologia a dispensa.

As entrevistas demonstraram que o imaginário coletivo acerca dos padrões de gênero é conservadora e rígida. Eles e elas associam os cursos a padrões tradicionais como, por exemplo: todo homem é forte e racional enquanto toda mulher é frágil e delicada.

Um outro dado coletado nas entrevistas diz respeito ao gosto pelas disciplinas que são ministradas. Todos os discentes disseram que as disciplinas de que mais gostam são aquelas que conseguem relacionar com a realidade, com a vida cotidiana, isto é, percebem uma aplicação do conhecimento para o exercício da profissão escolhida, o que evidencia 0 predomínio de uma visão pragmática entre elas e eles.

"as disciplinas que mais gostei foram as técnicas, porque consigo sanar as dúvidas que eu tive no trabalho e por saber que vou utilizá-las na prática" (Entrevistada 0).

"eu gostei de computação, desenho técnico e todas as físicas, porque foram matérias que eu consegui unir a teoria à prática" (Entrevistada M).

Do universo entrevistado, poucos foram os/as discentes que, na época da entrevista faziam estágio ou trabalhavam. Curiosamente, havia mais rapazes fazendo estágios do que moças, mas quando se verificou quais eram aqueles que já haviam sido efetivados como empregados, o número de moças foi maior.

Para muitos, é difícil conciliar o ritmo do curso com trabalho:

\footnotetext{
"no último semestre eu bati meu recorde, cheguei a ficar 72 horas acordada à base de café e muito energético (...) passei o mês todo dormindo de 3 a 5 horas por noite" (Entrevistada 0).

"a UTFPR não dá abertura para o aluno trabalhar e isso começa com a grade horária, ela não dá espaço para que os alunos busquem estágios ou contratações em empresas" (Entrevistada G).
}

Com relação às expectativas futuras de trabalho, os/as entrevistados/as foram unânimes ao declarar que pretendem trabalhar em uma grande empresa. 0 interessante dessas falas é que foram as moças que deixaram mais claro o desejo de seguir carreira dentro de uma grande empresa.

"eu pretendo ingressar numa grande empresa para fazer estágio e depois ser efetivada, para poder seguir carreira" (Entrevistada C).

"eu quero entrar numa empresa e ficar, eu não quero ficar pulando de galho em galho" (Entrevistada L).

Essas declarações, assim como de outras entrevistadas, demonstram que há uma maior preocupação por parte das meninas em ter um emprego certo e seguro. Essa preocupação pouco apareceu entre os rapazes. Todos disseram que querem trabalhar, mas não citam a preocupação em seguir uma carreira fixa em uma única empresa, o que permite afirmar que as estudantes de engenharia são mais preocupadas com a (in)segurança no mercado de trabalho.

$\mathrm{Na}$ maioria das falas dos rapazes transparece uma discriminação (mesmo que velada) acerca da presença de mulheres nos cursos de engenharia da UTFPR.

\begin{abstract}
"eu noto que as mulheres têm mais facilidades com as áreas de humanas e biológicas. A gente acha estranho que tenha meninas interessadas pela área de exatas". (Entrevistado R). "eu era a única menina da turma, aprendi a beber e jogar truco com os meninos. Eu era considerada a "burra" da turma". (Entrevistada G).
\end{abstract}

$\mathrm{Na}$ fala anterior, percebe-se claramente o conceito de estabelecidos e outsiders (Elias, citado por Lombardi, 2005), na qual a moça, para pertencer ao grupo, teve que assumir uma postura considerada "masculina", como beber e jogar truco (jogo de cartas). Assim, ela foi aceita, mas seu lugar dentro do grupo era periférico por ser mulher, o que permite dizer que ela pertencia ao grupo dos estabelecidos como uma outsider.

Em várias falas, os/as alunos/as não apontam explicitamente para uma imagem estereotipada do outro sexo, mas quando comentam sobre as brincadeiras em sala de aula ou sobre a idéia que eles têm com relação às suas colegas de turma, a discriminação fica evidente.

"Com relação às meninas, eles não conseguem enxergar a gente como futuras engenheiras, só como colegas. Quando 
a gente conversa com eles sobre estágio, sobre alguma coisa prática, eles acham que a gente não entende nada". (Entrevistada M).

Vale lembrar que a UTFPR, campus Curitiba, enquanto um ambiente predominantemente masculino contribui para que esses modelos machistas permaneçam, e sejam considerados "normais".

Um tema que surgiu nas entrevistas foi a sexualidade. Muitos/as se referiram aos atributos sexuais femininos, mas não aos masculinos. Tudo indica que há uma confusão permeando as relações sociais e nem sempre os entrevistados separam a mulher enquanto ser profissional e sexual.

"Na UTFPR, por ter mais homem do que mulher, as mulheres ficam se achando (mais importante do que ele). Elas te olham com o seguinte pensamento: quem é você, eu tenho 50 homens para escolher. Já os meninos ficam todos desesperados e ficam muito machistas (cheio de opiniões formadas sobre as meninas)". (Entrevistado R).

De acordo com a fala anterior, a mulher é vista como sedutora que, em virtude do grande número de homens, terá vantagens sobre os mesmos do ponto de vista sexual. Aqui se observa claramente o estereótipo da mulher-fatal, que irá se aproveitar dos homens-objetos, enquanto estes perpetuam os padrões de gênero socialmente construídos.

"... às vezes tem uns meninos que falam: você é a mulher do grupo, vai lá falar com o professor, muitos meninos acreditam que as meninas têm mais chance de conseguir algo com o professor". (Entrevistada L).

Alguns alunos acreditam que pelo fato de serem mulheres, as moças da turma que se dirigem ao professor, têm mais chances de serem atendidas em suas reivindicações, como por exemplo, uma mudança de data de prova ou dispensa de trabalho,

"os meninos não conseguem enxergar nas meninas futuras engenheiras, acho que eles pensam que a gente só vai casar e ter filhos." (Entrevistada M)

"... antes eu não perguntava muito aos professores para não parecer puxa-saco e com medo de que dissessem que eu passei porque sou mulher (como já ouvi os meninos falando de algumas meninas que só passaram em determinadas matérias porque foram chorar para os professores)". (Entrevistada 0).

Além da desvalorização da capacidade intelectual da colega, percebe-se uma preocupação das moças frente à sua sexualidade. Muitos rapazes vêem as boas notas de uma aluna como o resultado do uso de seus atributos sexuais frente ao professor, não acreditando na sua competência para 0 estudo.

Os relatos revelam que as moças dos diferentes cursos de engenharia têm que provar (das mais diferentes formas) que são melhores que os rapazes. A competição se dá em termos de desempenho e aplicação durante as aulas.

"no geral os alunos são muito machistas e preconceituosos. No começo, eu achava legal ser mulher no meio de tanto homem, mas depois começou a disputa, o stress de provar pra mim mesma, que eu sou tão boa quanto eles". (Entrevistada 0) "na minha turma tem meninos que concorrem com meninas. Tipo, pra ver quem vai melhor". (Entrevistado 0)

"os meninos têm muito preconceito, mas não é aquela coisa descarada. No começo a gente tem que mostrar que sabe. Por exemplo: no começo do semestre, um menino olha para você e não confia. Ele só passa a confiar, depois das provas, quando vêm as notas e a menina mostra que também é boa naquilo que faz". (Entrevistada S).

Sobre a questão do desempenho, Selke (2006) esclarece que a competência ou é negada às mulheres ou submetida a uma prova minuciosa. Para os homens a competência é considerada simplesmente e automaticamente um prérequisito. Por isso as estudantes têm a impressão de ter que se afirmar não somente perante os seus colegas, mas também perante os seus professores ${ }^{10}$.

0 desempenho escolar é um dado relevante nos cursos de engenharia. Os/as alunos/as, quando questionados sobre 0 assunto, sempre se referiam ao seu coeficiente (que na Instituição vai de 0-1). Curiosamente, poucos foram os/as entrevistados/as que estavam realmente satisfeitos com o próprio desempenho escolar. A média é 0,5, contudo, os/as alunos/as consideram ideal acima de 0,75. Quanto ao gênero diseram:

"os meninos têm mais facilidade em levar o curso do que as meninas. Eles levam de maneira mais "light'". (Entrevistado D)

ARBOR CLXXXIV 733 septiembre-octubre [2008] 889-904 ISSN: 0210-1963

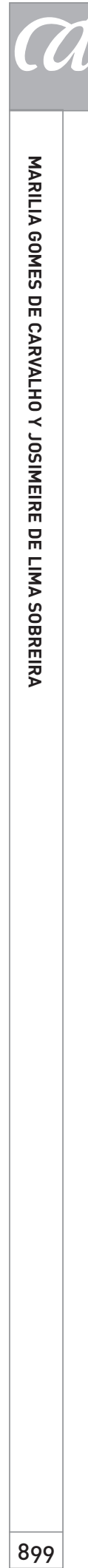


"as duas meninas da minha sala têm mais dificuldades. Quando tem relatório ou a disciplina é na área de humanas, elas se dão melhor. Em geral, as notas mais altas são dos meninos". (Entrevistado R)

De acordo com a maior parte dos/as entrevistados/as, as moças se esforçam muito mais do que os rapazes, e nem sempre conseguem obter um desempenho semelhante ao deles. Em geral, elas prestam mais atenção às aulas, estudam mais e fazem o curso com mais responsabilidade do que eles.

As diferenças entre o desempenho dos estudantes homens e mulheres apontam para a necessidade de um maior esforço que as mulheres devem fazer, como se elas não tivessem a mesma capacidade que eles têm para aprender:

"geralmente homem tem mais facilidade com matemática, física,... e mulher com línguas, português,... eu acho que as mulheres do curso têm mais dificuldade. Geralmente as meninas ficam meio perdidas quando a matéria é nova". (Entrevistada S)

"as meninas têm um desempenho pior do que os meninos. Têm que se dedicar mais para ter um desempenho igual ao dos meninos". (Entrevistada U)

Estas opiniões (das próprias estudantes) Ihes criam problemas:

"às vezes a gente vai mal, e isso mexe com a gente, e a atitude dos meninos só piora as coisas". (Entrevistada A) "penso que os meninos acham que somos "toscas", ou seja, que não somos suficientemente capazes para cursar engenharia" (Entrevistada $\mathrm{H}$ )

Esta desigualdade se manifesta da mesma forma quando se referem as expectativas quanto ao mercado de trabalho. Quando analisada a expectativa dos/as alunos/as diante da futura inserção neste mercado, todos/as foram unânimes ao declarar que os homens terão mais chances no mercado de trabalho. Sobre o assunto, Carvalho (2006), declara que a igualdade de competência não significa necessariamente igualdade de oportunidades no mercado de trabalho tecnológico.

"teve um aluno da minha turma que falou: não adianta você ter notas altas, se eu vou ter o melhor emprego por ser homem". (Entrevistada M) "os meninos terão mais chance, com absoluta, total e relevante certeza. Por experiência, há mais dificuldade por parte das meninas de conseguir um estágio. 0 mercado de trabalho aí fora não quer mulheres, porque é para trabalhar com peão, com técnicos, e geralmente a figura feminina com grau superior, é complicado". (Entrevistado B).

Esta opinião acaba é reforçada pela própria Instituição. No pátio da escola há um mural de chamada para estágios onde há muitos editais que deixam clara a preferência por estudantes do sexo masculino. A escola como receptora desses editais deveria verificar a razão para essa discriminação e não concordar com ela, exigindo que as empresas não fizessem opção pelo gênero do/a futuro/a estagiário/a.

"quando uma mulher chega num alto cargo, com certeza, ela teve que se esforçar muito mais do que um homem". (Entrevistada 0)

Quando analisada a ascensão profissional feminina, observa-se que há uma demora maior para que ela possa alcançar determinados postos de trabalho. Em geral a mulher deve mostrar um desempenho excepcional, e ainda uma rede de relações que contribua para que ela alcance patamares mais elevados dentro de uma empresa.

É curioso perceber que tanto os alunos, quanto as alunas observam essa possivel dificuldade futura. Cockburn, citado por Rapkiewicz $(1998,57)$ aponta que "quando a mulher resolve encarar um espaço considerado masculino (como no caso a engenharia), enfrenta o chamado custo da transgressão" (negrito das autoras).

"Quando uma engenheira vai a uma obra, ela não pode ir bem vestida. Ela deve ir de jeans, camiseta e tênis. Senão os homens mexem mesmo, além de ser perigoso. Eu, por exemplo, sou super vaidosa, mas sei que com esse tipo de roupa (saia, vestido, salto alto,..) não poderia visitar uma obra". (Entrevistada C)

Observa-se com esta fala que as moças vão, com o tempo adotando características consideradas masculinas, como se quisessem encobrir seus atributos sexuais. Assim, percebe-se o quanto a mulher-profissional é confundida com a sua sexualidade, fato este que pode dificultar a sua ação no mercado de trabalho. 
"as meninas que fazem engenharia e depois vão trabalhar com uma maioria de homens, com o tempo, também viram homens". (Entrevistada P)

Lombardi comenta que "as relações sociais de sexo que perpassam a área profissional da engenharia repousam, em primeiro lugar, sobre uma relação hierarquizada entre os sexos, tratando-se de uma relação de dominação e de poder do grupo de engenheiros do sexo masculino sobre o grupo de engenheiras" $(2005,131)$.

Observa-se, portanto, que há uma forte tensão entre os gêneros dentro dessa área, e ela vai acontecer tanto na universidade quanto no mercado de trabalho.

"Existem muitas diferenças sexuais no mercado de trabalho. Mulher não pode dar muita abertura, se der, já surgem comentários (do tipo que não é séria, que está querendo algo mais...). Por isso, ela acaba tendo que ter uma postura bem formal". (Entrevistado 0)

Os relatos demonstram que os critérios para a seleção em um emprego continuam sendo estabelecidos de acordo como os atributos masculinos e femininos construídos socialmente, o que faz com que as formas de inserção e manutenção no mercado de trabalho não sejam semelhantes para homens e mulheres.

"eu desejava ir para o ramo de software (automação, robótica) que é dominado por homens, mas sei que sofreria, por isso, acho que vou para o lado administrativo, seria mais fácil. Além disso, poderia conciliar melhor o lado de mãe, com o de engenheira". (Entrevistada A)

0 trecho anterior evidencia que a mulher (independente da idade) ainda está muito ligada ao espaço doméstico e à maternidade. Esta preocupação aparece também em outras entrevistas, mas nem sempre de maneira clara. As mulheres procuram por exemplos positivos que demonstram que é possível conciliar a evolução profissional como a formação de uma família (Selke, 2006).

Observa-se mais uma vez que, apesar de a maioria dos/as entrevistados/as serem jovens, há um predomínio da visão tradicional de família, na qual a mulher ainda se vê como a grande responsável pelos cuidados do lar. "eu sonho em casar, ter filhos, casar de branco na igreja. Cuidar da casa, dos filhos, do marido..." (Entrevistada S)

Diante dessa fala vê-se que os padrões de comportamento são conservadores, e disso resulta que muitas mulheres, mesmo com curso superior, dão prioridade ao lar e filhos, deixando para segundo plano a carreira profissional.

De acordo com os/as entrevistados/as, pode-se definir o/a profissional da engenharia da seguinte forma:

- engenheira: mais emocional, preocupada, detalhista e observadora, atenta aos relacionamentos humanos.

- engenheiro: mais competitivo, racional, prático e preocupado em realizar o seu trabalho de forma rápida e eficiente.

"as mulheres dão uma volta para fazer determinada coisa (acham defeito, são mais minuciosas). Já os homens não, são mais práticos, querem acabar logo". (Entrevistada C)

Percebe-se, através dos relatos, que a suposta presença de sensibilidade, paciência e detalhismo nas mulheres, pode ser um dos fatores que contribui para encaminhá-las para o setor administrativo das engenharias, principalmente para os recursos humanos, reforçando assim os estereótipos de gênero.

"No mercado de trabalho existe uma divisão, os engenheiros vão para a área de desenvolvimento (programação) e as engenheiras para a parte de relacionamento inter- pessoal. A área de desenvolvimento é uma área masculina, por exemplo, o meu currículo foi negado nesta área da Siemens, isto acontece porque na parte que exige mais lógica, racionalidade, tem maior concentração de homens, parece que o homem se relaciona melhor com a máquina". (Entrevistada G)

"Muitas dessas empresas grandes pedem estagiários dos sexo masculino (tipo a Volkswagen), aqui no mural da UTFPR. Não sei se tô errada, mas acho que os homens acreditam que vão se dar melhor que as mulheres". (Entrevistada L) "no mercado de trabalho, ainda há discriminação, por exemplo, na Renault, apenas 6\% dos engenheiros mecânicos são mulheres". (Entrevistada L)

0 relato anterior está de acordo com o que Lombardi comenta "o equilíbrio de forças que tende a se desenhar 
atualmente, entre o grupo de engenheiras e o de engenheiros em configurações como a escola de engenharia e os locais de trabalho, tende a favor do grupo masculino, maior numericamente, mais antigo na área profissional e, possivelmente, mais coeso" $(2005,132)$.

A conseqüência disso é que as estudantes de engenharia já antevêem dificuldades de ingresso no mercado de trabalho pelo simples fato de serem mulheres. Assim fala um aluno entevistado:

\begin{abstract}
"existem diferenças entre homens e mulheres no mercado de trabalho. Normalmente há um preconceito em relação à mulher (não sei por quê). Muitos estágios já vêm especificado que a vaga é para o sexo masculino. Eu acho que às vezes o cara que contrata esquece que tem mulher fazendo engenharia". (Entrevistado N).
\end{abstract}

No entanto, sobre o assunto, o diretor industrial que foi entrevistado, declarou que:

"... as mulheres engenheiras podem ser equiparadas aos homens, até porque elas estão cada vez mais dedicadas do que os homens".

"na hora da contratação não vejo diferenças sexuais, mas sim dentro da empresa. No dia-a-dia, o que vale é a opinião masculina". (Entrevistada G)

Um outro assunto enfatizado em muitas falas foi a idéia de que o/a engenheiro/a de hoje não é o mesmo de décadas passadas. Elas e eles devem ir além da técnica nos dias atuais; sobre isso, alguns entrevistados/as declararam que as mulheres teriam vantagens, pois possuem mais facilidade de se relacionar com as pessoas do que os homens.

"a maior virtude de um/a engenheiro hoje é saber lidar com pessoas, e sob pressão. Por isso, eu acho que as engenheiras se darão melhor, pois sabem lidar melhor com relacionamentos humanos". (Entrevistada G)

Verificou-se, portanto, que tanto alunos quanto alunas percebem as diferenças de gênero existentes no mercado de trabalho. Mas isso não significa um obstáculo para a conclusão dos seus estudos por parte das mulheres, apenas uma preocupação que foi relatada por quase todas as estudantes, independentemente do curso que estejam fazendo.

\section{Considerações FINAIS}

Através deste trabalho, foi possível verificar que os cursos de engenharia são uma fonte privilegiada para os estudos de gênero. Ao escolherem estes cursos as moças estão rompendo barreiras, pois quebram os estereótipos de que mulheres não gostam de números e não servem para exercer profissões da área tecnológica.

É fato que as mulheres permanecem em um número reduzido dentro dos cursos de engenharia, mas também é evidente que as relações de gênero dentro destes cursos estão se alterando. Atualmente ingressam mais moças nos cursos de engenharia do que em um passado recente.

Mas, será que essas moças conseguem também romper com o modelo dicotômico de gênero? Vimos que as mudanças estão acontecendo, no entanto, as estudantes e os estudantes continuam reproduzindo modelos de masculinidade e feminilidade tradicionais. A mulher ainda é percebida (e se percebe), como um ser humano mais vinculado ao espaço privado, assim como o homem está mais relacionado ao espaço público. Portanto, os padrões de comportamento estereotipados permanecem ou são alterados muito lentamente. Inclusive, alguns entrevistados vislumbraram o futuro de suas colegas, como mães e esposas dedicadas e não como profissionais competentes. Também as estudantes incorporaram este papel.

As mulheres ganharam mais espaço fora do lar, mas os homens não ocuparam mais espaço dentro do ambiente doméstico. Isto explica a preocupação de muitas estudantes em tentar conciliar a vida familiar (casa, marido e filhos) com a vida profissional. Entre os rapazes esta preocupação não está presente, o que reforça mais uma vez, a permanência de modelos tradicionais.

As escolas possuem um papel importante para a perpetuação destes modelos dicotômicos, pois têm feito muito pouco para modificá-los. Seria interessante que as professoras e professores de Ensino Fundamental e Médio promovessem a conscientização das meninas e meninos para as questões de gênero. Assim, esse paradigma tradicional e conservador poderia ser rompido mais facilmente.

Vale ressaltar que essa virada de milênio mostrou que as mulheres estão ingressando cada vez mais em áreas do 
conhecimento como a ciência e a tecnologia. Portanto, outros espaços estão se abrindo para as mulheres que estão pouco a pouco ampliando sua presença. Isto significa que as mulheres estão considerando novas possibilidades de escolhas profissionais, e estão indo além dos padrões de gênero tradicionalmente construídos.

No entanto permanece a necessidade de se analisar mais profundamente como a exclusão das mulheres (brasileiras ou não) dentro das carreiras científicas e tecnológicas é provocada por práticas discriminatórias (ainda que nem sempre conscientes) e quais os efeitos dessa exclusão. A segregação se manifesta dentro do próprio campo das engenharias, pois grande parte das engenheiras trabalha com pesquisa e gestão o que significa que estão excluídas do processo de geração de novas tecnologias, setor considerado masculino. A pesquisa revelou que, apesar de optarem pela engenharia, muitas moças acreditam que sofrerão algum tipo de discriminação no mercado de trabalho pelo simples fato de serem mulheres. À mulher cabe conquistar esse espaço, que já está sofrendo mudanças $e_{\text {, }}$ ao que tudo indica, mudanças favoráveis, tanto nos cursos de engenharia quanto no mercado de trabalho.

Os resultados das entrevistas mostraram também que entre as moças que estudam engenharia ou trabalham nesta área há uma tendência a adotar modelos de comportamento considerados masculinos. Em alguns casos as moças procuram se vestir de maneira "neutra" ou "unisex" (o que significa no padrão masculino) para não chamar a atenção no ambiente universitário ou de trabalho, encobrindo assim sua feminilidade. Este fato reflete uma adaptação da mulher no espaço "dos homens" e coloca em cheque os padrões de comportamento femininos na esfera pública.
As técnicas de pesquisa qualitativa foram decisivas, pois vislumbraram na prática aquilo que já havia sido percebido pelos dados quantitativos, além de permitirem interpretar como são vividas no cotidiano do universo estudantil tradicionalmente masculino, as experiências das (e dos) estudantes. Foi possivel vislumbrar que o mercado de trabalho permanece desencorajando as futuras engenheiras. Elas sabem que não terão as mesmas oportunidades que os engenheiros devido à maior valorização do trabalho masculino e à atribuição de valores e salários hierarquizados para homens e mulheres.

0 predomínio da representação de que os papéis de gênero devem ser dicotomizados, definindo determinados cursos e profissões aos homens e outros às mulheres é uma visão equivocada da realidade. Deve-se valorizar a pluralidade de modelos masculinos e femininos e combater os padrões tradicionais que, além de estimularem a discriminação e preconceitos entre homens e mulheres nas atividades voltadas à ciência e tecnologia, estimulam relações de poder que estão calcadas em estereótipos de gênero e não no desempenho e competência profissional.

Finalmente, é possivel concluir que há uma permanência de representações androcêntricas nas áreas de ciência e tecnologia e, especificamente, nas engenharias. Entretanto não se pode negar que estão ocorrendo mudanças, ainda que de forma lenta e gradativa. As mulheres estão saindo de sua invisibilidade e caminhando em direção a um espaço que também pode ser seu. Afinal de contas, a percepção feminina de mundo pode trazer grandes contribuições a todas as áreas do conhecimento.

\section{NOTES}

1 Esta pesquisa resultou na dissertação de Mestrado de Josimeire Lima Sobreira intitulada "Estudantes de Engenharia na UTFPR: uma abordagem de genero", defendida em 2006 no Programa de Pós-Graduação em Tecnologia da Universidade Tecnológica Federal do Paraná, sob orientação da
Professora Doutora Marilia Gomes de Carvalho.

2 Ver, por exemplo, Velho, L. e Léon, E. (1998), Rapkiewicz, C. E. (1998) Tabak, F. (2002 e 2003), Facciotti, M C. e Samara, E. M. (2004), Lombardi, M. R. (2004, 2005 e 2006), Cabral, C. (2006) e Sobreira, J. L. (2006).

3 Ver Garcia, J. Z. e Escamilla, R. R. (2005) e Rius, L. F. (2005).
Recibido: 10 de mayo de 2007 Aceptado: 10 de julio de 2007 
4 Ver Carvalho, M. G.; Feitosa, S. e Silva, V. C. (2006).

5 Informações disponíveis no endereço eletrônico da Instituição www.utfpr. com.br

6 Informações sobre a instituição disponiveis no endereço eletrônico: http://www.ct.cefetpr.br/historia. htm\#. Acessado em 20/01/2005.

7 De acordo com a historia da UTFPR, os campi eram inicialmente unidades descentralizadas do antigo CEFET-PR. Hoje encontram-se centralizados em regime de sistema universitario.

8 Dados disponíveis no endereço eletrônico: www.utfpr.edu.br. Acessado em 27/05/2006.

9 Dados não disponíveis sobre matriculas deste ano. Tem início em 1992.

10 Este estudo foi realizado na Alemanha, com o objetivo de comparar as questões de gênero com a realidade brasileira no ensino tecnológico. No entanto, sua afirmação demonstra que os estereótipos e as discriminações acerca da participação da mulher no mundo da ciência e tecnologia, ocorrem tanto no Brasil quanto na Alemanha.

\section{REFERÊNCIAS}

Cabral, Carla (2006): O Conhecimento Dialogicamente Situado: histórias de vida, valores humanistas e consciência crítica de professoras do Centro Tecnológico da UFSC, Tese de Doutorado.
Programa de Pós-Graduação em Educação Científica e Tecnológica. Universidade Federal de Santa Catarina.

Carvalho, Marilia Gomes de; Feitosa; Samara; Silva e Valter Cardoso da (2006): "Relações de Gênero entre alunos e alunas em uma Instituição de Educação Tecnológica Brasileira", Revista Tecnologia e Sociedade, 3, pp. 85-134.

Facciotti, Maria Cândida R. e Samara, Eni M. de (coords.) (2004): Mulheres Politécnicas: histórias e perfis, São Paulo, EDUSP.

García, Judith Z; Escamilla, Rocío, R. y Reyes, Gracia, A. (2005): "Aunque la mona tenga posgrados, mona se queda: la falta de equidad de género en el mercado laboral", en Graf, Norma B. y Flores, Javier (eds.), Ciencia, Tecnología e Género en Iberoamérica, Ciudad de México, Universidad Nacional Autónoma de México, pp. 125-143.

Lombardi, Maria R. (2004): "Mulheres engenheiras no mercado de trabalho brasileiro: qual seu lugar?", Revista Mulher e Trabalho, 4: 45-60.

- (2005): Perseverança e Resistência: a engenharia como profissão feminina, Tese de Doutorado, Unicamp.

- (2006): "Engenheiras Brasileiras: inserção e limites de gênero no campo profissional", Cadernos de Pesquisa, 36: 173-202.

Rapkiewicz, Clevi E. (1998): Femina Computationalis ou A Construção do Gênero na Informática, Tese de Doutorado, Universidade Federal do Rio de Janeiro.
Rius, Lourdes. F. (2005): "Gênero y mujeres académicas: hasta dónde la equidad", en Graf, Norma B. y Flores, Javier (eds.). Ciencia, Tecnología y Gênero en Iberoamérica, Cidade do México: Universidad Nacional Autónoma de México, pp. 331-352.

Saraiva, Karla, S. (2004): Fabricando Identidades em Escolas de Engenharia, Disponivel em: www.rizoma.com.br. Acessado em 13/09/2004.

Schienbinger, Londa (2001): O Feminismo mudou a Ciência?, São Paulo, EDUSC.

Selke, Stefan (2006): "A complexidade da consciência sexual indiferente - Resultado de uma pesquisa entre estudantes da Fachhochschule Furtwangen", Revista Tecnologia e Sociedade, 3, pp. 135-170.

Sobreira, Josimeire de L. (2006): Estudantes de Engenharia: uma abordagem de gênero, Dissertação de Mestrado, Programa de Pós-Graduação em Tecnologia, Universidade Tecnológica Federal do Paraná.

Tabak, Fanny (2002): O Laboratório de Pandora: Estudos sobre a ciência no feminino, Rio de Janeiro, Garamond.

Tabak, Fanny (2003): "Gênero, Conhecimento, Ciência e Poder", en Carvalho, M. E. P. e Pereira, M. Z. C. (orgs.), Revista Gênero e Educação, Ed. Universitária, Universidade Federal da Paraíba, pp. 15-31.

Velho, Léa e Léon, E. (1998): "A construção social da produção científica por mulheres", Cadernos Pagu, 10: 309-344. 